\title{
Uma etiologia incomum de síndroma de má absorção
}

Beatriz Pavão Braga, Nuno Almeida, Clara Paiva

\section{RESUMO}

Introdução: Os distúrbios da absorção dizem respeito a um largo espetro de condições com múltiplas etiologias e manifestações clínicas variadas. Este caso demonstra um efeito adverso raro do olmesartan-medoxomilo, que se manifestou de forma indolente. Com este relato de caso pretende-se chamar a atenção para a necessidade da revisão terapêutica como ponto fulcral no estudo etiológico de uma síndroma de má absorção, bem como elucidar alguns diagnósticos diferenciais mais frequentes. Descrição do caso: Mulher de 60 anos, com antecedentes de hipertensão arterial diagnosticada em 2013 e medicada com olmesartan desde essa altura. Apresentou quadro de diarreia com mais de quatro semanas de evolução; iniciou-se investigação, que foi inconclusiva dada a regressão espontânea do quadro. Cerca de quatro meses depois apresentou vómitos e perda de peso, tendo-se progredido na investigação etiológica que foi inconclusiva. Após alteração do anti-hipertensor, as queixas desapareceram por completo.

Comentário: A síndroma de má absorção, tendo como agente causal o olmesartan-medoxomilo, é um diagnóstico raro, mas que pode ter consequências graves para o doente. Recomenda-se que nos doentes medicados com olmesartan e que desenvolvam estes sintomas, na ausência de outra causa, o fármaco seja descontinuado.

Palavras-chave: Olmesartan; Má absorção; Olmesartan-medoxomilo.

\section{INTRODUÇÃO}

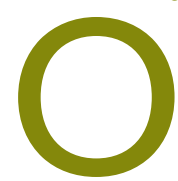

s distúrbios da absorção dizem respeito a um largo espetro de condições com múltiplas etiologias e manifestações clínicas variadas. Na sua maioria, estão associados a diminuição da absorção intestinal de um ou mais nutrientes da dieta e são referidos como síndroma de má absorção. ${ }^{1}$ A má absorção implica um desequilíbrio mantido entre a disponibilidade e as necessidades de nutrientes ${ }^{2}$ e pode resultar de múltiplos mecanismos:

Estes distúrbios devem ser incluídos no diagnóstico diferencial de diarreia e de défices nutricionais. O olmesartan-medoxomilo é um antagonista dos recetores da angiotensina II, aprovado para o tratamento da hipertensão arterial e utilizado desde 2002. Pode estar associado, entre outros efeitos adversos, a enteropatia sprue-like ou mesmo síndroma de má absorção.

\section{DESCRIÇÃO DO CASO}

Doente do sexo feminino com 60 anos de idade, caucasiana, assistente administrativa, solteira, tipologia fa-

Serviço de Medicina Interna, Hospital do Divino Espírito Santo de Ponta Delgada, E.P.E. miliar unitária, natural e residente em Portugal, com antecedentes de hipertensão arterial diagnosticada desde 2013, medicada desde então com olmesartanmedoxomilo 40mg. Sem alergias medicamentosas conhecidas, hábitos etílicos ou tabágicos e sem antecedentes familiares de relevo.

Em agosto de 2015 apresentou quadro de diarreia com duas semanas de evolução, caracterizado por três a quatro dejeções diárias, líquidas, raramente com resíduos alimentares, predominantemente diurnas mas ocasionalmente noturnas, sem sangue, muco ou pus. Referiu vómitos associados, ocasionais, alimentares. Negou fatores desencadeantes ou outros sintomas acompanhantes, nomeadamente febre, artralgias, alterações cutâneas, febre, dor abdominal, perda ponderal ou esteatorreia. Recorreu a uma consulta de gastrenterologia, tendo realizado estudo analítico que não demonstrou alterações (hemograma, função renal, parâmetros hepáticos, função tiroideia) e endoscopia digestiva alta, que revelou gastropatia congestiva-exame anatomopatológico, atrofia, deformação das vilosidades, sugestiva de doença celíaca. Iniciou dieta sem glúten, sem melhoria das queixas. Quatro meses depois, em novembro de 2015, por manter vómitos e diarreia 
QUADRO I. Condições que são causa de má absorção, categorizadas pela fase de absorção prejudicada

Etiologia

1. Alterações no lúmen intestinal

a. Hidrólise de substratos

- Deficiência/inativação de enzima digestiva

b. Solubilização de gordura

- Redução da síntese de sais biliares

- Alteração da secreção biliar

- Desconjugação de sais biliares

- Aumento da perda de sais biliares

c. Disponibilidade luminal de nutrientes específicos

- Diminuição do ácido gástrico

- Diminuição do fator intrínseco

- Consumo bacteriano de nutrientes

d. Fármacos

2. Defeitos na superfície absortiva epitelial

a. Hidrólise membrana luminal

- Defeitos adquiridos/congénitos de dissacarídeos

b. Transporte epitelial

3. Alterações pós-absorção

Fonte: Adaptado de UpToDate.com ${ }^{3}$

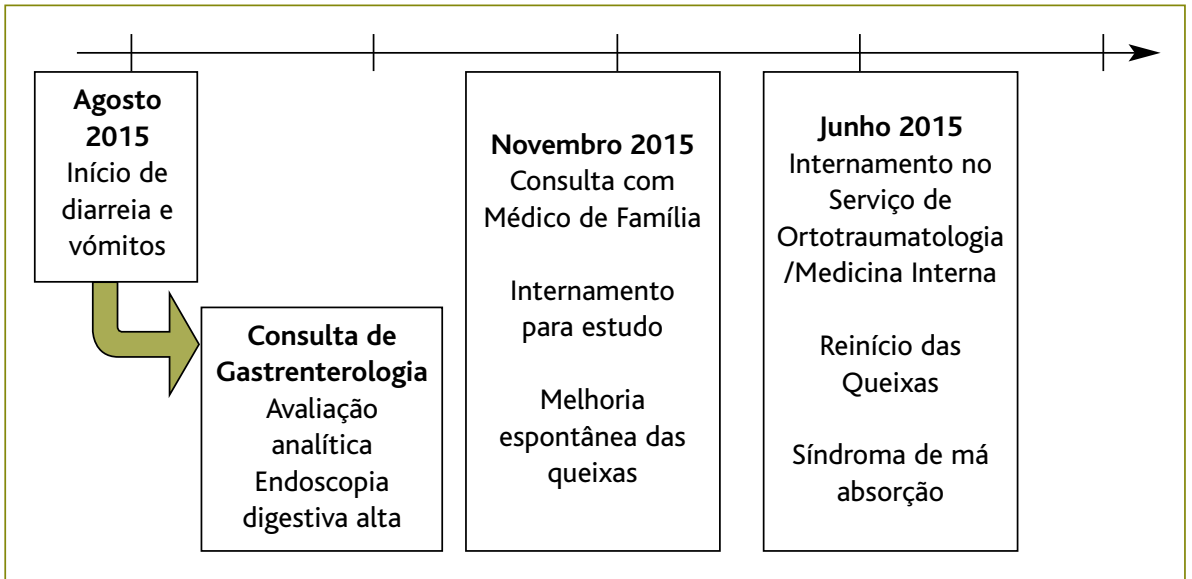

Figura 1. Cronograma de apoio ao caso clínico.

de características semelhantes e apresentar emagrecimento, recorreu ao seu médico de família que a encaminhou para consulta de medicina interna, tendo sido internada para estudo. Realizou novamente endoscopia digestiva alta (visualização de mucosa do fundo e corpo gástrico com hiperemia difusa, apagamento das pregas e discreta fissuração de D2; anatomia patológica de biópsia D2 e bulbo com atrofia vilositária subtotal e escasso infiltrado do epitélio com padrão não favorável ao diagnóstico de doença celíaca), videocápsula (visualizada atrofia de toda a mucosa do intestino delgado com fissuração/nodularidade da mucosa, sem úlceras ou lesões vegetantes) e TC de abdómen (ansas ileais de parede espessada, com densificação nodular da gordura subjacente). Por melhoria das queixas, a doente teve alta clinicamente bem, mas sem o diagnóstico esclarecido.

Seis meses depois, em março de 2016, foi internada por fratura do úmero esquerdo, resultante de uma queda da própria altura por desequilíbrio e fraqueza generalizada. Apresentava nessa altura dois a três episódios de vómitos/dia, alimentares, sem outra sintomatologia associada, exceto sensação de fraqueza generalizada e com perda de cerca de sete quilos de peso corporal. Ao exame objetivo encontrava-se pálida, ligeiramente desidratada, normotensa, emagrecida, abdómen mole e depressível, sem dor à palpação ou organomegalias palpáveis. Em avaliação analítica neste internamento apresentou défice de magnésio $(1,3 \mathrm{mg} / \mathrm{dl})$, potássio $(2,5 \mathrm{mmol} / \mathrm{L})$, fósforo $(1,5 \mathrm{mg} / \mathrm{dl})$, cálcio total 
corrigido $(8 \mathrm{mg} / \mathrm{dl})$, hipoalbuminemia $(4,9 \mathrm{~g} / \mathrm{dL})$ e prolongamento do tempo de protrombina (18 seg.). Após cirurgia ortopédica foi transferida para o serviço de medicina interna para estudo de provável síndroma de má absorção. Repetiu endoscopia digestiva alta (gastropatia congestiva-anatomia patológica: gastrite crónica superficial, com ligeiros sinais de atividade, associada à presença de Helicobacter pylori; sem displasia ou neoplasia), endoscopia por cápsula (aparente atrofia/edema do jejuno proximal, recuperação progressiva das vilosidades ao longo do restante jejuno, lingangiectasias ao longo de todo o delgado, mais evidentes nos segmentos distais), colonoscopia (sem alterações observáveis), TC de abdómen (sem alterações observáveis) e exclusão de doença celíaca por testes serológicos convencionais negativos, ausência dos heterodímeros HLA classe II (HLA-DQ2/8). De salientar a ausência de melhoria clínica após início de dieta sem glúten, que já teria iniciado anteriormente. Cumpriu terapêutica de erradicação do Helicobacter pylori, sem melhoria das queixas. Foi posteriormente alterado o anti-hipertensor para lercanidipina, com resolução dos défices nutricionais e das queixas. Encontra-se em seguimento pelo seu médico de família.

\section{COMENTÁRIO}

Descreve-se um caso clínico de má absorção que melhorou após suspensão do olmesartan-medoxomilo. Algumas das reações adversas descritas do fármaco, com uma frequência de 1-10\%, descrevem diarreia (um dos efeitos adversos mais comuns) e sintomas de enteropatia sprue-like, ${ }^{4}$ sendo que casos de enteropatia atribuíveis ao olmesartan têm sido publicados desde 2012, ${ }^{5}$ descrevendo uma diarreia crónica com perda de peso significativa. Esta sintomatologia pode desenvolver-se meses a anos depois de iniciar o tratamento. Comummente encontra-se atrofia das vilosidades na biópsia intestinal. ${ }^{4,6}$

Apesar dos mecanismos da enteroparia sprue-like associada ao olmesartan ainda serem incertos, alguns autores sugerem uma hipersensibilidade retardada local ou resposta imunitária mediada por células ao prófármaco olmesartan-medoxomilo. ${ }^{7}$ Outros sugerem que a inibição da TGF-beta mediada por ARA, um mediador importante na homeostase intestinal, seja um mecanismo possível, apesar de não ser claro porque é que este efeito não é observado por outros ARAs. ${ }^{8} \mathrm{~A}$ enteropatia não foi detetada com outros antagonistas dos recetores da angiotensina II, que não o olmesartan. ${ }^{7}$ É necessária mais investigação para elucidar o mecanismo da enteropatia associada ao olmesartan.

A FDA ${ }^{7}$ recomenda que os doentes medicados com olmesartan-medoxomilo que desenvolvem estes sintomas, e nos quais nenhuma outra causa é encontrada, suspendam este fármaco e iniciem terapêutica com outro anti-hipertensor.

Este caso enfatiza a importância de uma história clínica completa e da investigação diagnóstica, destacando um efeito adverso de um fármaco frequentemente utilizado na prática clínica. A enteropatia induzida por olmesartan é uma nova entidade clínica que deve ser incluída no diagnóstico diferencial de atrofia vilosa com serologia celíaca negativa. ${ }^{9}$

O olmesartan-medoxomilo é excretado na bílis e urina, sofrendo mínima metabolização $0^{10} \mathrm{e}$ com biodisponibilidade de 26\%. ${ }^{11}$ Estes autores estudaram vários self-micro emulsifying drug delivery system, facilmente emulsificados em meio aquoso sob agitação e motilidade gástrica, aumentando a biodisponibilidade do fármaco em $170 \% .{ }^{11}$ Este poderá ser um mecanismo que, no futuro, evitará efeitos adversos gastrointestinais.

Concluindo, a síndroma de má absorção tendo como agente causal o olmesartan-medoxomilo é um diagnóstico raro e de exclusão. Deverá ser feito o diagnóstico diferencial com outras etiologias de má absorção. $\mathrm{O}$ atraso no diagnóstico e na atuação pode ter consequências graves, com perda de peso significativa, défices nutricionais e redução da qualidade de vida. Recomenda-se que nos doentes medicados com olmesartan que desenvolvem estes sintomas, e nos quais nenhuma outra causa seja encontrada, o fármaco seja descontinuado.

\section{REFERÊNCIAS BIBLIOGRÁFICAS}

1. Kasper DL, Fauci AS, Hauser SL, Longo DL, Jameson JL, Loscalzo J, editors. Harrison's principles of internal medicine (Vol. II). 19th ed. New York: McGraw-Hill; 2015. ISBN 9780071802154

2. Feldman M, Friedman LS, Brandt LJ. Sleisenger and Fordtran's gastrointestinal and liver disease (Vol. I: pathophysiology, diagnosis, management). 9th ed. Philadelphia: Saunders Elsevier; 2010. ISBN 9781416061892

3. Mason JB. Approach to the adult patient with suspected malabsorption [updated 2019 Apr 9]. In: UpToDate.com [Internet]. Available from: 
https://www.uptodate.com/contents/approach-to-the-adult-patientwith-suspected-malabsorption?search=malabsorption\&source =search_result\&selectedTitle $=1 \sim 150 \&$ usage_type $=$ default $\&$ dis play_rank=1

4. Lexicomp ${ }^{\circledR}$ database. Olmesartan: drug information [updated 2019]. In: UpToDate.com [Internet]. Available from: https://www.uptodate .com/contents/olmesartan-drug-information? search=Olmesartan:\%20drug\%20information\&source=panel_search_result\&selectedTitle $=1 \sim 18 \&$ usage_type=panel\&kp_tab=drug_general\&display_ra $n k=1$

5. DeGaetani M, Tennyson CA, Lebwohl B, Lewis SK, Abu Daya H, Arguelles-Grande $C$, et al.Villous atrophy and negative celiac serology: a diagnostic and therapeutic dilemma. Am J Gastroenterol. 2013;108(5):64753.

6. Dreifuss SE, Tomizawa Y, Farber NJ, Davison JM, Sohnen AE. Spruelike enteropathy associated with olmesartan: an unusual case of severe diarrhea. Case Rep Gastrointest Med. 2013;2013:618071.

7. Food \& Drug Administration. FDA drug safety communication: FDA approves label changes to include intestinal problems (sprue-like enteropathy) linked to blood pressure medicine olmesartan medoxomil [homepage]. Silver Spring: U.S. FDA; 2016 Feb 2 [cited 2017 Apr 3].Available from: https://www.fda.gov/drugs/drug-safety-and-availability/ fda-drug-safety-communication-fda-approves-label-changes-includeintestinal-problems-sprue
8. Rubio-Tapia A, Herman ML, Ludvigsson JF, Kelly DG, Mangan TF, Wu TT, et al. Severe spruelike enteropathy associated with olmesartan. Mayo Clin Proc. 2012;87(8):732-8.

9. Carneiro L, Moreira A, Pereira A, Andrade C, Soares J, Silva A. Olmesartan-induced sprue like enteropathy. GE Port J Gastreoenterol. 2016;23(2):101-5.

10. Yamada A, Maeda K, Kamiyama E, Sugiyama D, Kondo T, Shiroyanagi Y, et al. Multiple human isoforms of drug transporters contribute to the hepatic and renal transport of olmesartan, a selective antagonist of the angiotensin II AT1-receptor. Drug Metab Dispos. 2007;35(12):2166-76.

11. Lee BS, Kang MJ, Choi WS, Choi YB, Kim HS, Lee SK, et al. Solubilized formulation of olmesartan medoxomil for enhancing oral bioavailability. Arch Pharm Res. 2009;32(11):1629-35.

\section{CONFLITO DE INTERESSES}

Os autores declaram não possuir quaisquer conflitos de interesse.

\author{
ENDEREÇO PARA CORRESPONDÊNCIA \\ Beatriz Pavão Braga \\ E-mail: beatriz.braga@gmail.com \\ https://orcid.org/0000-0002-7141-381X
}

Recebido em 23-11-2017

Aceite para publicação em 17-09-2018

\section{ABSTRACT}

\section{AN UNCOMMON ETIOLOGY OF MALABSORPTION SYNDROME}

Introduction: Absorption disorders concern a broad spectrum of conditions with multiple etiologies and clinical manifestations. This case demonstrates a rare adverse effect of olmesartan-medoxomil. This case report intends to draw attention to the need for therapeutic revision as a crucial point in the etiological study of malabsorption syndrome, as well as to name more frequent differential diagnoses.

Case description: 60-year-old woman, with a history of hypertension diagnosed in 2013 and medicated with olmesartan since then. She presented with diarrhea for more than four weeks. As the etiological investigation began, she spontaneously improved, so it was left incomplete. About four months later, she presented with vomiting and weight loss, and the etiological investigation was inconclusive. After the antihypertensive was changed, the complaints disappeared completely.

Comment: Malabsorption syndrome caused by olmesartan-medoxomil is a rare diagnosis, but can have serious consequences for the patient. It is recommended that in patients on olmesartan and who develop these symptoms, in the absence of another cause, the drug is discontinued.

Keywords: Olmesartan; Malabsorption; Olmesartan-medoxomil. 